\title{
Finding Parts in Very Large Corpora
}

\author{
Matthew Berland, Eugene Charniak \\ $m b, e c @ c s . b r o w n . e d u$ \\ Department of Computer Science \\ Brown University, Box 1910 \\ Providence, RI 02912
}

\begin{abstract}
We present a method for extracting parts of objects from wholes (e.g. "speedometer" from "car"). Given a very large corpus our method finds part words with $55 \%$ accuracy for the top 50 words as ranked by the system. The part list could be scanned by an end-user and added to an existing ontology (such as WordNet), or used as a part of a rough semantic lexicon.
\end{abstract}

\section{Introduction}

We present a method of extracting parts of objects from wholes (e.g. "speedometer" from "car"). To be more precise, given a single word denoting some entity that has recognizable parts, the system finds and rank-orders other words that may denote parts of the entity in question. Thus the relation found is strictly speaking between words, a relation Miller [1] calls "meronymy." In this paper we use the more colloquial "part-of" terminology.

We produce words with $55 \%$ accuracy for the top 50 words ranked by the system, given a very large corpus. Lacking an objective definition of the part-of relation, we use the majority judgment of five human subjects to decide which proposed parts are correct. The program's output could be scanned by an enduser and added to an existing ontology (e.g., WordNet), or used as a part of a rough semantic lexicon.

To the best of our knowledge, there is no published work on automatically finding parts from unlabeled corpora. Casting our nets wider, the work most similar to what we present here is that by Hearst [2] on acquisition of hyponyms ("isa" relations). In that paper Hearst (a) finds lexical correlates to the hyponym relations by looking in text for cases where known hyponyms appear in proximity (e.g., in the construction (NP, NP and (NP other NN)) as in "boats, cars, and other vehicles"), (b) tests the proposed patterns for validity, and (c) uses them to extract relations from a corpus. In this paper we apply much the same methodology to the part-of relation. Indeed, in [2]
Hearst states that she tried to apply this strategy to the part-of relation, but failed. We comment later on the differences in our approach that we believe were most important to our comparative success.

Looking more widely still, there is an evergrowing literature on the use of statistical/corpusbased techniques in the automatic acquisition of lexical-semantic knowledge ([3-8]). We take it as axiomatic that such knowledge is tremendously useful in a wide variety of tasks, from lower-level tasks like noun-phrase reference, and parsing to user-level tasks such as web searches, question answering, and digesting. Certainly the large number of projects that use WordNet [1] would support this contention. And although WordNet is hand-built, there is general agreement that corpus-based methods have an advantage in the relative completeness of their coverage, particularly when used as supplements to the more laborintensive methods.

\section{Finding Parts}

\subsection{Parts}

Webster's Dictionary defines "part" as "one of the often indefinite or unequal subdivisions into which something is or is regarded as divided and which together constitute the whole." The vagueness of this definition translates into a lack of guidance on exactly what constitutes a part, which in turn translates into some doubts about evaluating the results of any procedure that claims to find them. More specifically, note that the definition does not claim that parts must be physical objects. Thus, say, "novel" might have "plot" as a part.

In this study we handle this problem by asking informants which words in a list are parts of some target word, and then declaring majority opinion to be correct. We give more details on this aspect of the study later. Here we simply note that while our subjects often disagreed, there was fair consensus that what might count as a part depends on the nature of the 


\begin{tabular}{|l|}
\hline Pattern A \\
\hline $\begin{array}{l}\text { headlight windshield ignition shifter dashboard ra- } \\
\text { diator brake tailpipe pipe airbag speedometer con- } \\
\text { verter hood trunk visor vent wheel occupant en- } \\
\text { gine tyre }\end{array}$ \\
\hline \hline Pattern B \\
\hline $\begin{array}{l}\text { trunk wheel driver hood occupant seat bumper } \\
\text { backseat dashboard jalopy fender rear roof wind- } \\
\text { shield back clunker window shipment reenactment } \\
\text { axle }\end{array}$ \\
\hline \hline Pattern C \\
\hline $\begin{array}{l}\text { passenger gunmen leaflet hop houseplant airbag } \\
\text { gun koran cocaine getaway motorist phone men } \\
\text { indecency person ride woman detonator kid key }\end{array}$ \\
\hline \hline Pattern D \\
\hline $\begin{array}{l}\text { import caravan make dozen carcass shipment hun- } \\
\text { dred thousand sale export model truckload queue } \\
\text { million boatload inventory hood registration trunk } \\
\text { ten }\end{array}$ \\
\hline \hline Pattern E \\
\hline $\begin{array}{l}\text { airbag packet switch gem amateur device handgun } \\
\text { passenger fire smuggler phone tag driver weapon } \\
\text { meal compartment croatian defect refugee delay }\end{array}$ \\
\hline
\end{tabular}

Table 2: Grammatical Pattern Comparison

Our seeds are one word (such as "car") and its plural. We do not claim that all single words would fare as well as our seeds, as we picked highly probable words for our corpus (such as "building" and "hospital") that we thought would have parts that might also be mentioned therein. With enough text, one could probably get reasonable results with any noun that met these criteria.

\subsection{Statistical Methods}

The program has three phases. The first identifies and records all occurrences of patterns $A$ and $B$ in our corpus. The second filters out all words ending with "ing", "ness", or "ity", since these suffixes typically occur in words that denote a quality rather than a physical object. Finally we order the possible parts by the likelihood that they are true parts according to some appropriate metric.

We took some care in the selection of this metric. At an intuitive level the metric should be something like $p(w \mid p)$. (Here and in what follows $w$ denotes the outcome of the random variable generating wholes, and $p$ the outcome for parts. $W(w)$ states that $w$ appears in the patterns $\mathrm{AB}$ as a whole, while $P(p)$ states that $p$ appears as a part.) Metrics of the form $p(w \mid p)$ have the desirable property that they are invariant over $p$ with radically different base frequencies, and for this reason have been widely used in corpus-based lexical semantic research $[3,6,9]$. However, in making this intuitive idea someone more precise we found two closely related versions:

$$
\begin{aligned}
& p(w, W(w) \mid p) \\
& p(w, W(w) \mid p, P(p))
\end{aligned}
$$

We call metrics based on the first of these "loosely conditioned" and those based on the second "strongly conditioned".

While invariance with respect to frequency is generally a good property, such invariant metrics can lead to bad results when used with sparse data. In particular, if a part word $p$ has occurred only once in the data in the $\mathrm{AB}$ patterns, then perforce $p(w \mid p)$ $=1$ for the entity $w$ with which it is paired. Thus this metric must be tempered to take into account the quantity of data that supports its conclusion. To put this another way, we want to pick $(w, p)$ pairs that have two properties, $p(w \mid p)$ is high and $|w, p|$ is large. We need a metric that combines these two desiderata in a natural way.

We tried two such metrics. The first is Dunning's [10] log-likelihood metric which measures how "surprised" one would be to observe the data counts $|w, p|,|\neg w, p|,|w, \neg p|$ and $|\neg w, \neg p|$ if one assumes that $p(w \mid p)=p(w)$. Intuitively this will be high when the observed $p(w \mid p) \gg p(w)$ and when the counts supporting this calculation are large.

The second metric is proposed by Johnson (personal communication). He suggests asking the question: how far apart can we be sure the distributions $p(w \mid p)$ and $p(w)$ are if we require a particular significance level, say .05 or .01 . We call this new test the "significant-difference" test, or sigdiff. Johnson observes that compared to sigdiff, log-likelihood tends to overestimate the importance of data frequency at the expense of the distance between $p(w \mid p)$ and $p(w)$.

\subsection{Comparison}

Table 3 shows the 20 highest ranked words for each statistical method, using the seed word "car." The first group contains the words found for the method we perceive as the most accurate, sigdiff and strong conditioning. The other groups show the differences between them and the first group. The + category means that this method adds the word to its list, means the opposite. For example, "back" is on the sigdiff-loose list but not the sigdiff-strong list.

In general, sigdiff worked better than surprise and strong conditioning worked better than loose conditioning. In both cases the less favored methods tend to promote words that are less specific ("back" over "airbag", "use" over "radiator"). Furthermore, the 


\begin{tabular}{|l|l|}
\hline \multicolumn{2}{|l|}{ Sigdiff, Strong } \\
\hline & $\begin{array}{l}\text { airbag brake bumper dashboard driver fender } \\
\text { headlight hood ignition occupant pipe radi- } \\
\text { ator seat shifter speedometer tailpipe trunk } \\
\text { vent wheel windshield }\end{array}$ \\
\hline \hline Sigdiff, Loose \\
\hline+ & back backseat oversteer rear roof vehicle visor \\
\hline- & $\begin{array}{l}\text { airbag brake bumper pipe speedometer } \\
\text { tailpipe vent }\end{array}$ \\
\hline \hline Surprise, Strong \\
\hline+ & $\begin{array}{l}\text { back cost engine owner price rear roof use } \\
\text { value window }\end{array}$ \\
\hline- & $\begin{array}{l}\text { airbag bumper fender ignition pipe radiator } \\
\text { shifter speedometer tailpipe vent }\end{array}$ \\
\hline \hline Surprise, Loose \\
\hline+ & $\begin{array}{l}\text { back cost engine front owner price rear roof } \\
\text { side value version window }\end{array}$ \\
\hline- & $\begin{array}{l}\text { airbag brake bumper dashboard fender ig- } \\
\text { nition pipe radiator shifter speedometer } \\
\text { tailpipe vent }\end{array}$ \\
\hline
\end{tabular}

Table 3: Methods Comparison

combination of sigdiff and strong conditioning worked better than either by itself. Thus all results in this paper, unless explicitly noted otherwise, were gathered using sigdiff and strong conditioning combined.

\section{Results}

\subsection{Testing Humans}

We tested five subjects (all of whom were unaware of our goals) for their concept of a "part." We asked them to rate sets of 100 words, of which 50 were in our final results set. Tables $6-11$ show the top 50 words for each of our six seed words along with the number

\begin{tabular}{|l||l|l|l|}
\hline & book & building & car \\
\hline 10 & 8 & 7 & 8 \\
20 & 14 & 12 & 17 \\
30 & 20 & 18 & 23 \\
40 & 24 & 21 & 26 \\
50 & 28 & 29 & 31 \\
\hline \hline & hospital & plant & school \\
\hline 10 & 7 & 5 & 10 \\
20 & 16 & 10 & 14 \\
30 & 21 & 15 & 20 \\
40 & 23 & 20 & 26 \\
50 & 26 & 22 & 31 \\
\hline
\end{tabular}

Table 4: Result Scores of subjects who marked the word as a part of the seed concept. The score of individual words vary greatly but there was relative consensus on most words. We put an asterisk next to words that the majority subjects marked as correct. Lacking a formal definition of part, we can only define those words as correct and the rest as wrong. While the scoring is admittedly not perfect $^{1}$, it provides an adequate reference result.

Table 4 summarizes these results. There we show the number of correct part words in the top 10, 20, 30, 40, and 50 parts for each seed (e.g., for "book", 8 of the top 10 are parts, and 14 of the top 20). Overall, about $55 \%$ of the top 50 words for each seed are parts, and about $70 \%$ of the top 20 for each seed. The reader should also note that we tried one ambiguous word, "plant" to see what would happen. Our program finds parts corresponding to both senses, though given the nature of our text, the industrial use is more common. Our subjects marked both kinds of parts as correct, but even so, this produced the weakest part list of the six words we tried.

As a baseline we also tried using as our "pattern" the head nouns that immediately surround our target word. We then applied the same "strong conditioning, sigdiff" statistical test to rank the candidates. This performed quite poorly. Of the top 50 candidates for each target, only $8 \%$ were parts, as opposed to the $55 \%$ for our program.

\subsection{WordNet}

\begin{tabular}{|c|l|}
\hline WordNet \\
\hline+ & $\begin{array}{l}\text { door engine floorboard gear grille horn mirror } \\
\text { roof tailfin window }\end{array}$ \\
\hline- & $\begin{array}{l}\text { brake bumper dashboard driver headlight ig- } \\
\text { nition occupant pipe radiator seat shifter } \\
\text { speedometer tailpipe vent wheel windshield }\end{array}$ \\
\hline
\end{tabular}

Table 5: WordNet Comparison

We also compared out parts list to those of WordNet. Table 5 shows the parts of "car" in WordNet that are not in our top $20(+)$ and the words in our top 20 that are not in WordNet $(-)$. There are definite tradeoffs, although we would argue that our top20 set is both more specific and more comprehensive. Two notable words our top 20 lack are "engine" and "door", both of which occur before 100. More generally, all WordNet parts occur somewhere before 500, with the exception of "tailfin", which never occurs with car. It would seem that our program would be

\footnotetext{
'For instance, "shifter" is undeniably part of a car, while "production" is only arguably part of a plant.
} 
a good tool for expanding Wordnet, as a person can scan and mark the list of part words in a few minutes.

\section{Discussion and Conclusions}

The program presented here can find parts of objects given a word denoting the whole object and a large corpus of unmarked text. The program is about $55 \%$ accurate for the top 50 proposed parts for each of six examples upon which we tested it. There does not seem to be a single cause for the $45 \%$ of the cases that are mistakes. We present here a few problems that have caught our attention.

Idiomatic phrases like "a jalopy of a car" or "the son of a gun" provide problems that are not easily weeded out. Depending on the data, these phrases can be as prevalent as the legitimate parts.

In some cases problems arose because of tagger mistakes. For example, "re-enactment" would be found as part of a "car" using pattern B in the phrase "the re-enactment of the car crash" if "crash" is tagged as a verb.

The program had some tendency to find qualities of objects. For example, "driveability" is strongly correlated with car. We try to weed out most of the qualities by removing words with the suffixes "ness", "ing", and "ity."

The most persistent problem is sparse data, which is the source of most of the noise. More data would almost certainly allow us to produce better lists, both because the statistics we are currently collecting would be more accurate, but also because larger numbers would allow us to find other reliable indicators. For example, idiomatic phrases might be recognized as such. So we see "jalopy of a car" (two times) but not, of course, "the car's jalopy". Words that appear in only one of the two patterns are suspect, but to use this rule we need sufficient counts on the good words to be sure we have a representative sample. At 100 million words, the NANC is not exactly small, but we were able to process it in about four hours with the machines at our disposal, so still larger corpora would not be out of the question.

Finally, as noted above, Hearst [2] tried to find parts in corpora but did not achieve good results. She does not say what procedures were used, but assuming that the work closely paralleled her work on hyponyms, we suspect that our relative success was due to our very large corpus and the use of more refined statistical measures for ranking the output.

\section{Acknowledgments}

This research was funded in part by NSF grant IRI9319516 and ONR Grant N0014-96-1-0549. Thanks to the entire statistical NLP group at Brown, and particularly to Mark Johnson, Brian Roark, Gideon Mann, and Ana-Maria Popescu who provided invaluable help on the project.

\section{References}

[1] George Miller, Richard Beckwith, Cristiane Fellbaum, Derek Gross \& Katherine J. Miller, "WordNet: an on-line lexical database," International Journal of Lexicography 3 (1990), 235-245.

[2] Marti Hearst, "Automatic acquisition of hyponyms from large text corpora," in Proceedings of the Fourteenth International Conference on Computational Linguistics, 1992.

[3] Ellen Riloff \& Jessica Shepherd, "A corpus-based approach for building semantic lexicons," in Proceedings of the Second Conference on Empirical Methods in Natural Language Processing, 1997, 117-124.

[4] Dekang Lin, "Automatic retrieval and clustering of similar words," in 36th Annual Meeting of the Association for Computational Linguistics and 17th International Conference on Computational Linguistics, 1998, 768-774.

[5] Gregory Grefenstette, "SEXTANT: extracting semantics from raw text implementation details," Heuristics: The Journal of Knowledge Engineering (1993).

[6] Brian Roark \& Eugene Charniak, "Noun-phrase co-occurrence statistics for semi-automatic semantic lexicon construction," in 36th Annual Meeting of the Association for Computational Linguistics and 17th International Conference on Computational Linguistics, 1998, 1110-1116.

[7] Vasileios Hatzivassiloglou \& Kathleen R. McKeown, "Predicting the semantic orientation of adjectives," in Proceedings of the 35th Annual Meeting of the ACL, 1997, 174-181.

[8] Stephen D. Richardson, William B. Dolan \& Lucy Vanderwende, "MindNet: acquiring and structuring semantic information from text," in 36th Annual Meeting of the Association for Computational Linguistics and 17th International Conference on Computational Linguistics, 1998, 10981102.

[9] William A. Gale, Kenneth W. Church \& David Yarowsky, "A method for disambiguating word senses in a large corpus," Computers and the $\mathrm{Hu}$ manities (1992).

[10] Ted Dunning, "Accurate methods for the statistics of surprise and coincidence," Computational Linguistics 19 (1993), 61-74. 


\begin{tabular}{|c|c|c|c|}
\hline Ocr. & Frame & Word & $x / 5$ \\
\hline 853 & 3069 & author & $5^{*}$ \\
\hline 23 & 48 & subtitle & $4^{*}$ \\
\hline 114 & 414 & co-author & $4^{*}$ \\
\hline 7 & 16 & foreword & $5^{*}$ \\
\hline 123 & 963 & publication & 2 \\
\hline 5 & 10 & epigraph & $3^{*}$ \\
\hline 9 & 32 & co-editor & $4^{*}$ \\
\hline 51 & 499 & cover & $5^{*}$ \\
\hline 220 & 3053 & copy & 2 \\
\hline 125 & 1961 & page & $5^{*}$ \\
\hline 103 & 1607 & title & $5^{*}$ \\
\hline 6 & 28 & authorship & 2 \\
\hline 13 & 122 & manuscript & 2 \\
\hline 45 & 771 & chapter & $5^{*}$ \\
\hline 4 & 14 & epilogue & $5^{*}$ \\
\hline 69 & 1693 & publisher & $4^{*}$ \\
\hline 16 & 240 & jacket & $5^{*}$ \\
\hline 48 & 1243 & subject & $5^{*}$ \\
\hline 2 & 2 & double-page & 0 \\
\hline 289 & 10800 & sale & 0 \\
\hline 12 & 175 & excerpt & 2 \\
\hline 45 & 1512 & content & $5^{*}$ \\
\hline 16 & 366 & plot & $5^{*}$ \\
\hline 3 & 10 & galley & 2 \\
\hline 57 & 2312 & edition & $3^{*}$ \\
\hline 8 & 123 & protagonist & $4^{*}$ \\
\hline 3 & 13 & co-publisher & $3^{*}$ \\
\hline 6 & 82 & spine & $5^{*}$ \\
\hline 13 & 360 & premise & 1 \\
\hline 11 & 295 & revelation & 2 \\
\hline 30 & 1390 & theme & 2 \\
\hline 3 & 16 & fallacy & 2 \\
\hline 53 & 3304 & editor & $5^{*}$ \\
\hline 9 & 252 & translation & 2 \\
\hline 44 & 2908 & character & $5^{*}$ \\
\hline 23 & 1207 & tone & 2 \\
\hline 8 & 218 & flaw & 2 \\
\hline 56 & 4265 & section & $4^{*}$ \\
\hline 15 & 697 & introduction & $5^{*}$ \\
\hline 47 & 3674 & release & 1 \\
\hline 2 & 5 & diarist & 0 \\
\hline 3 & 22 & preface & $4^{*}$ \\
\hline 6 & 140 & narrator & $4^{*}$ \\
\hline 8 & 276 & format & 2 \\
\hline 3 & 25 & facsimile & 0 \\
\hline 3 & 26 & mock-up & 1 \\
\hline 5 & 111 & essay & 2 \\
\hline 35 & 3648 & back & $5^{*}$ \\
\hline 6 & 194 & heroine & $4^{*}$ \\
\hline 7 & 300 & pleasure & 0 \\
\hline
\end{tabular}

Table 6: book

\begin{tabular}{|c|c|c|c|}
\hline Ocr. & Frame & Word & $x / 5$ \\
\hline 72 & 154 & rubble & 0 \\
\hline 527 & 2116 & floor & $5^{*}$ \\
\hline 42 & 156 & facade & $4^{*}$ \\
\hline 85 & 456 & basement & $5^{*}$ \\
\hline 100 & 577 & roof & $5^{*}$ \\
\hline 9 & 23 & atrium & $4^{*}$ \\
\hline 32 & 162 & exterior & $5^{*}$ \\
\hline 28 & 152 & tenant & 1 \\
\hline 12 & 45 & rooftop & $4^{*}$ \\
\hline 49 & 333 & wreckage & 1 \\
\hline 7 & 20 & stairwell & $5^{*}$ \\
\hline 30 & 250 & shell & 0 \\
\hline 14 & 89 & demolition & 0 \\
\hline 14 & 93 & balcony & $5^{*}$ \\
\hline 10 & 60 & hallway & $5^{*}$ \\
\hline 23 & 225 & renovation & 0 \\
\hline 4 & 9 & janitor & 1 \\
\hline 10 & 62 & rotunda & $5^{*}$ \\
\hline 36 & 432 & entrance & $3^{*}$ \\
\hline 7 & 37 & hulk & 0 \\
\hline 82 & 1449 & wall & $5^{*}$ \\
\hline 23 & 276 & ruin & 0 \\
\hline 37 & 572 & lobby & $5^{*}$ \\
\hline 12 & 120 & courtyard & $4^{*}$ \\
\hline 3 & 6 & tenancy & 0 \\
\hline 13 & 156 & debris & 1 \\
\hline 9 & 83 & pipe & 2 \\
\hline 32 & 635 & interior & $3^{*}$ \\
\hline 219 & 6612 & front & $4^{*}$ \\
\hline 7 & 58 & elevator & $5^{*}$ \\
\hline 11 & 143 & evacuation & 1 \\
\hline 2 & 2 & web-site & 0 \\
\hline 2 & 2 & airshaft & $4^{*}$ \\
\hline 2 & 2 & cornice & $3^{*}$ \\
\hline 47 & 1404 & construction & 2 \\
\hline 9 & 115 & landlord & 1 \\
\hline 14 & 285 & occupant & 1 \\
\hline 129 & 5616 & owner & 1 \\
\hline 17 & 404 & rear & $3^{*}$ \\
\hline 25 & 730 & destruction & 1 \\
\hline 15 & 358 & superintendent & 1 \\
\hline 3 & 11 & stairway & $5^{*}$ \\
\hline 6 & 72 & cellar & $5^{*}$ \\
\hline 3 & 12 & half-mile & 0 \\
\hline 37 & 1520 & step & $5^{*}$ \\
\hline 10 & 207 & corridor & $5^{*}$ \\
\hline 39 & 1646 & window & $5^{*}$ \\
\hline 2 & 3 & subbasement & $5^{*}$ \\
\hline 38 & 1736 & door & $4^{*}$ \\
\hline 4 & 31 & spire & $3^{*}$ \\
\hline
\end{tabular}

Table 7: building 


\begin{tabular}{|c|c|c|c|}
\hline Ocr. & Frame & Word & $x / 5$ \\
\hline 92 & 215 & trunk & $4^{*}$ \\
\hline 27 & 71 & windshield & $5^{*}$ \\
\hline 12 & 24 & dashboard & $5^{*}$ \\
\hline 13 & 30 & headlight & $5^{*}$ \\
\hline 70 & 318 & wheel & $5^{*}$ \\
\hline 9 & 21 & ignition & $4^{*}$ \\
\hline 43 & 210 & hood & $5^{*}$ \\
\hline 119 & 880 & driver & 1 \\
\hline 6 & 13 & radiator & $5^{*}$ \\
\hline 4 & 6 & shifter & 1 \\
\hline 37 & 285 & occupant & 1 \\
\hline 15 & 83 & brake & $5^{*}$ \\
\hline 5 & 12 & vent & $3^{*}$ \\
\hline 6 & 18 & fender & $5^{*}$ \\
\hline 3 & 4 & tailpipe & $5^{*}$ \\
\hline 8 & 42 & bumper & $5^{*}$ \\
\hline 11 & 83 & pipe & $3^{*}$ \\
\hline 7 & 36 & airbag & $5^{*}$ \\
\hline 108 & 1985 & seat & $4^{*}$ \\
\hline 3 & 5 & speedometer & $4^{*}$ \\
\hline 3 & 6 & converter & 2 \\
\hline 3 & 6 & backseat & $5^{*}$ \\
\hline 64 & 1646 & window & $5^{*}$ \\
\hline 28 & 577 & roof & $5^{*}$ \\
\hline 2 & 2 & jalopy & 0 \\
\hline 33 & 784 & engine & $5^{*}$ \\
\hline 20 & 404 & rear & $4^{*}$ \\
\hline 4 & 19 & visor & $3^{*}$ \\
\hline 6 & 68 & deficiency & 0 \\
\hline 75 & 3648 & back & 2 \\
\hline 2 & 3 & oversteer & 1 \\
\hline 10 & 216 & plate & $3^{*}$ \\
\hline 9 & 179 & cigarette & 1 \\
\hline 3 & 13 & clunker & 0 \\
\hline 7 & 117 & battery & $5^{*}$ \\
\hline 18 & 635 & interior & $3^{*}$ \\
\hline 19 & 761 & speed & 1 \\
\hline 11 & 334 & shipment & 0 \\
\hline 5 & 73 & re-enactment & 0 \\
\hline 3 & 18 & conditioner & 2 \\
\hline 3 & 18 & axle & $5^{*}$ \\
\hline 11 & 376 & $\operatorname{tank}$ & $5^{*}$ \\
\hline 6 & 125 & attribute & 0 \\
\hline 18 & 980 & location & 1 \\
\hline 71 & 6326 & cost & 1 \\
\hline 5 & 88 & paint & $4^{*}$ \\
\hline 4 & 51 & antenna & $5^{*}$ \\
\hline 2 & 5 & socket & 0 \\
\hline 2 & 5 & corsa & 0 \\
\hline 6 & 151 & tire & $5^{*}$ \\
\hline
\end{tabular}

Table 8: car

\begin{tabular}{|c|c|c|c|}
\hline Ocr. & Frame & Word & $x / 5$ \\
\hline 43 & 302 & ward & $5^{*}$ \\
\hline $\mathbf{3}$ & 7 & radiologist & $5^{*}$ \\
\hline 2 & 2 & trograncic & 0 \\
\hline 3 & 9 & mortuary & $4^{*}$ \\
\hline 3 & 9 & hopewell & 0 \\
\hline 17 & 434 & clinic & $5^{*}$ \\
\hline $\mathbf{3}$ & 11 & aneasthetist & $5^{*}$ \\
\hline 18 & 711 & ground & 1 \\
\hline 16 & 692 & patient & $4^{*}$ \\
\hline 33 & 2116 & floor & 4* \\
\hline 68 & 5404 & unit & $4^{*}$ \\
\hline 44 & 3352 & room & 2 \\
\hline 11 & 432 & entrance & $4^{*}$ \\
\hline 19 & 1237 & doctor & $5^{*}$ \\
\hline 15 & 1041 & administrator & $5^{*}$ \\
\hline 6 & 207 & corridor & $4^{*}$ \\
\hline 25 & 2905 & staff & $3^{*}$ \\
\hline 35 & 5015 & department & $5^{*}$ \\
\hline 7 & 374 & bed & $5^{*}$ \\
\hline 2 & 11 & pharmacist & $4^{*}$ \\
\hline 100 & 23692 & director & $5^{*}$ \\
\hline 5 & 358 & superintendent & $3^{*}$ \\
\hline 3 & 89 & storage & $3^{*}$ \\
\hline 20 & 5347 & chief & 2 \\
\hline 4 & 299 & lawn & 2 \\
\hline 4 & 306 & compound & 0 \\
\hline 29 & 13944 & head & $\mathbf{0}$ \\
\hline $\mathbf{3}$ & 149 & nurse & $5^{*}$ \\
\hline 2 & 33 & switchboard & $4^{*}$ \\
\hline 3 & 156 & debris & 0 \\
\hline 14 & 5073 & executive & 2 \\
\hline 2 & 35 & pediatrician & $4^{*}$ \\
\hline 17 & 7147 & board & 1 \\
\hline 13 & 4686 & area & 1 \\
\hline 4 & 416 & ceo & 2 \\
\hline 5 & 745 & yard & 2 \\
\hline 15 & 6612 & front & $3^{*}$ \\
\hline 8 & 2200 & reputation & 1 \\
\hline 3 & 190 & inmate & 1 \\
\hline 4 & 457 & procedure & 2 \\
\hline 2 & 42 & overhead & 0 \\
\hline 14 & 6315 & committee & $4^{*}$ \\
\hline 5 & 875 & mile & 0 \\
\hline 15 & 7643 & center & 1 \\
\hline 2 & 46 & pharmacy & $4^{*}$ \\
\hline 4 & 518 & laboratory & $5^{*}$ \\
\hline 16 & 8788 & program & 1 \\
\hline 2 & 48 & shah & 0 \\
\hline 29 & 25606 & president & 2 \\
\hline 3 & 276 & ruin & 1 \\
\hline
\end{tabular}

Table 9: hospital 


\begin{tabular}{|c|c|c|c|}
\hline Ocr. & Frame & Word & $\mathrm{x} / 5$ \\
\hline 185 & 1404 & construction & 2 \\
\hline 5 & 12 & stalk & $4^{*}$ \\
\hline 23 & 311 & reactor & $3^{*}$ \\
\hline 8 & 72 & emission & $3^{*}$ \\
\hline 10 & 122 & modernization & 1 \\
\hline 2 & 2 & melter & $3^{*}$ \\
\hline 19 & 459 & shutdown & 1 \\
\hline 6 & 62 & start-up & 0 \\
\hline 41 & 1663 & worker & 2 \\
\hline 22 & 844 & root & $3^{*}$ \\
\hline 17 & 645 & closure & 0 \\
\hline 22 & 965 & completion & 0 \\
\hline 26 & 1257 & operator & $4^{*}$ \\
\hline 12 & 387 & inspection & 2 \\
\hline 21 & 980 & location & 2 \\
\hline 19 & 856 & gate & $3^{*}$ \\
\hline 2 & 4 & sprout & $3^{*}$ \\
\hline 4 & 41 & leaf & $5^{*}$ \\
\hline 26 & 1519 & output & 2 \\
\hline 3 & 20 & turbine & $3^{*}$ \\
\hline 12 & 506 & equipment & $3^{*}$ \\
\hline 4 & 51 & residue & 1 \\
\hline 2 & 5 & zen & 0 \\
\hline 3 & 22 & foliage & $4^{*}$ \\
\hline 8 & 253 & conversion & 0 \\
\hline 8 & 254 & workforce & 1 \\
\hline 8 & 309 & seed & $3^{*}$ \\
\hline 17 & 1177 & design & $4^{*}$ \\
\hline 9 & 413 & fruit & $5^{*}$ \\
\hline 23 & 1966 & expansion & 2 \\
\hline 5 & 131 & pollution & 2 \\
\hline 50 & 6326 & cost & 1 \\
\hline 24 & 2553 & tour & 0 \\
\hline 24 & 2564 & employee & $5^{*}$ \\
\hline 29 & 3478 & site & 1 \\
\hline 40 & 5616 & owner & $3^{*}$ \\
\hline 9 & 577 & roof & $4^{*}$ \\
\hline 49 & 7793 & manager & $3^{*}$ \\
\hline 41 & 6360 & operation & $3^{*}$ \\
\hline 6 & 276 & characteristic & 1 \\
\hline 21 & 2688 & production & $3^{*}$ \\
\hline 3 & 48 & shoot & 0 \\
\hline 32 & 5404 & unit & 1 \\
\hline 6 & 337 & tower & 1 \\
\hline 5 & 233 & co-owner & 1 \\
\hline 2 & 13 & instrumentation & $3^{*}$ \\
\hline 8 & 711 & ground & 2 \\
\hline 3 & 69 & fiancee & 0 \\
\hline 5 & 296 & economics & 1 \\
\hline 7 & 632 & energy & 2 \\
\hline
\end{tabular}

Table 10: plant

\begin{tabular}{|c|c|c|c|}
\hline Ocr. & Frame & Word & $x / 5$ \\
\hline 525 & 1051 & dean & $4^{*}$ \\
\hline 164 & 445 & principal & $5^{*}$ \\
\hline 134 & 538 & graduate & $3^{*}$ \\
\hline 11 & 24 & prom & $3^{*}$ \\
\hline $\begin{array}{llll}7 & & \end{array}$ & 12 & headmistress & $4^{*}$ \\
\hline 16 & 61 & alumni & $3^{*}$ \\
\hline 19 & 79 & curriculum & $5^{*}$ \\
\hline 4 & 5 & seventh-grader & $3^{*}$ \\
\hline 8 & 22 & gymnasium & $5^{*}$ \\
\hline 25 & 134 & faculty & $5^{*}$ \\
\hline $\mathbf{3}$ & 3 & crit & 0 \\
\hline 13 & 87 & endowment & $\mathbf{3}^{*}$ \\
\hline 8 & 40 & alumnus & 2 \\
\hline 9 & 57 & cadet & 0 \\
\hline 11 & 82 & enrollment & 2 \\
\hline 5 & 18 & infirmary & $4^{*}$ \\
\hline 3 & 5 & valedictorian & $4^{*}$ \\
\hline 8 & 52 & commandant & 0 \\
\hline 75 & 1462 & student & $5^{*}$ \\
\hline 56 & 1022 & feet & 0 \\
\hline 10 & 100 & auditorium & $5^{*}$ \\
\hline 4 & 15 & jamieson & 0 \\
\hline 5 & 26 & yearbook & $3^{*}$ \\
\hline 8 & 71 & cafeteria & $4^{*}$ \\
\hline 28 & 603 & teacher & $5^{*}$ \\
\hline 4 & 17 & grader & 2 \\
\hline 2 & 2 & wennberg & 0 \\
\hline 2 & 2 & jeffe & $0^{\prime}$ \\
\hline 7 & 65 & pupil & $3^{*}$ \\
\hline 21 & 525 & campus & 4* \\
\hline 11 & 203 & class & $5^{*}$ \\
\hline 17 & 423 & trustee & $3^{*}$ \\
\hline 8 & 115 & counselor & $4^{*}$ \\
\hline 7 & 108 & benefactor & 2 \\
\hline 5 & 56 & berth & 0 \\
\hline $\mathbf{5}$ & 60 & hallway & $4^{*}$ \\
\hline 7 & 130 & mascot & $\mathbf{3}^{*}$ \\
\hline 39 & 2323 & founder & 1 \\
\hline 2 & 4 & raskin & 0 \\
\hline 6 & 112 & playground & $4^{*}$ \\
\hline 105 & 8788 & program & $\mathbf{3}^{*}$ \\
\hline 16 & 711 & ground & $3^{*}$ \\
\hline 6 & 120 & courtyard & $\mathbf{3}^{*}$ \\
\hline 25 & 1442 & hall & $4^{*}$ \\
\hline 17 & 837 & championship & 1 \\
\hline $\mathbf{3}$ & 20 & accreditation & 2 \\
\hline 6 & 135 & fellow & 1 \\
\hline 2 & 5 & freund & 0 \\
\hline 4 & 53 & rector & 2 \\
\hline 6 & 144 & classroom & $4^{*}$ \\
\hline
\end{tabular}

Table 11: school 